\title{
Espécies medicinais do Brasil com potencial anti-inflamatório ou antioxidante: Uma
}

\section{revisão}

\author{
Medicinal species from Brazil with anti-inflammatory or antioxidant potential: A review \\ Especies medicinales de Brasil con potencial antiinflamatorio o antioxidante: Una revision
}

Recebido: 17/05/2021 | Revisado: 27/05/2021 | Aceito: 01/06/2021 | Publicado: 15/06/2021

\author{
Joedna Cavalcante Pereira \\ ORCID: https://orcid.org/0000-0002-2246-0337 \\ Universidade Federal do Piauí, Brasil \\ E-mail: joednacp@gmail.com \\ Analina Beserra Martins \\ ORCID: https://orcid.org/0000-0002-3854-1422 \\ Universidade Federal do Piaú, Brasil \\ E-mail: nalainnee@gmail.com \\ Melissa Carvalho Franca Rocha \\ ORCID: https://orcid.org/0000-0002-2881-8926 \\ Universidade Federal do Piaú, Brasil \\ E-mail: melllbiomedi@gmail.com \\ Salomão Mascarenhas Cavalcante Júnior \\ ORCID: https://orcid.org/0000-0002-8348-5255 \\ Universidade Federal do Piauí, Brasil \\ E-mail: salomaomcjunior@hotmail.com \\ Chistiane Mendes Feitosa \\ ORCID: https://orcid.org/0000-0001-8013-1761 \\ Universidade Federal do Piauí, Brasil \\ E-mail: chistiane@ufpi.edu.br
}

\begin{abstract}
Resumo
As plantas medicinais são utilizadas pela população desde tempos imemoriais, representando uma fonte notável para o tratamento de diversas doenças humanas, que podem ter seu risco reduzido pela ingestão de produtos à base destas plantas, benefícios que são atribuídos a alguns metabólitos secundários que apresentam uma diversidade de atividades, dentre elas destacam-se a antiinflamatória e/ou antioxidante. O objetivo desse trabalho é realizar um levantamento bibliográfico buscando as espécies mais utilizadas de plantas medicinais do Brasil com potencial anti-inflamatório e antioxidante da última década. Foram utilizadas publicações indexadas nas bases de dados PubMed, Science Direct e Scielo nos últimos 10 anos, utilizando os seguintes descritores: "Brazilian medicinal plants", "anti-inflammatory activity" e "antioxidant activity" Utilizando o marcador booleano "AND" assegurando a especificidade nas buscas. Foram identificados 1.185 artigos, onde 1.140 foram eliminados por não atenderem aos critérios de inclusão ou exclusão. O total de 45 artigos foram incluídos, categorizados de acordo com a utilização para atividade antiinflamatória e atividade antioxidante. Dentre os compostos ativos com atividades anti-inflamatórias tem-se alguns compostos polifenólicos, além de alcalóide, terpenóide e esteróides. Estes metabólitos secundários atuam em diferentes alvos envolvidos no processo inflamatório. Os estudos têm demonstrado que os compostos polifenólicos, principalmente os flavonoides, apresentam propriedades antioxidantes que podem ser utilizados para fins terapêuticos em doenças como crônico-degenerativas. Esses resultados sugerem as perspectivas de estudos futuros para se obter uma melhor compreensão dos componentes individuais e o uso desses compostos como um possível agente terapêutico para patologias como a inflamação e aumento de radicais livres.
\end{abstract}

Palavras-chave: Plantas medicinais; Atividade anti-inflamatória; Atividade antioxidante.

\begin{abstract}
Medicinal plants have been used by the population since time immemorial, representing a remarkable source for the treatment of various human diseases, that may have their risk reduced by eating products based on these plants, benefits are attributed to some secondary metabolites that have an anti-inflammatory and/or antioxidant activity. The aim of this study is to perform a literature searching for the most commonly used species of medicinal plants in Brazil with antiinflammatory and antioxidant potential of the last decade. Were used publications indexed in the databases: PubMed, Science Direct and Scielo in the last 10 years, using the following descriptors: "Brazilian medicinal plants", "antiinflammatory activity" and "antioxidant activity" Using the Boolean marker "AND" ensuring specificity in searches. 1,185 articles were identified, 1.140 were eliminated because they did not meet the inclusion or exclusion criteria. A total of 45 articles published were included, which were categorized according to the use for anti-inflammatory and
\end{abstract}


antioxidant activity. Among the active compounds with anti-inflammatory activities there are some polyphenolic compounds, in addition to alkaloid, terpenoid and steroid. These secondary metabolites act on different targets involved in the inflammatory process. Studies have shown that polyphenolic compounds, especially flavonoids, have bioactive compounds with antioxidant properties that can be used for therapeutic purposes in diseases such as chronic degenerative diseases. These results suggest the prospects for future studies to obtain a better understanding of the individual components and the use of these compounds as a possible therapeutic agent for pathologies such as inflammation and free radicals.

Keywords: Medicinal plants; Anti-inflammatory activity; Antioxidant activity.

\section{Resumen}

Las plantas medicinales han sido utilizadas por la población desde tiempos inmemoriales, representando una fuente notable para el tratamiento de diversas enfermedades. Pueden ver reducido su riesgo al consumir productos de origen vegetal, beneficios que se atribuyen a algunos metabolitos secundarios que tienen una variedad de actividades, entre las que destacan el antiinflamatorio y/o antioxidante. El objetivo de este trabajo es realizar un relevamiento bibliográfico buscando las especies de plantas medicinales más utilizadas en Brasil con potencial antiinflamatorio y antioxidante de la última década. Se utilizaron publicaciones indexadas en las bases de datos: PubMed, Science Direct y Scielo, durante los últimos 10 años, utilizando los siguientes descriptores: "Brazilian medicinal plants", "anti-inflammatory activity" y "antioxidant activity". Usar el marcador booleano "AND" para garantizar la especificidad en las búsquedas. Identificaron 1,185 artículos, de los cuales 1,140 fueron eliminados por no cumplir con los criterios de inclusión o exclusión. Incluyeron un total de 45 artículos, categorizados según el uso de productos naturales. Entre los compuestos activos con actividad antiinflamatoria se encuentran algunos compuestos polifenólicos, alcaloides, terpenoides y esteroides. Estos metabolitos actúan sobre diferentes dianas implicadas en el proceso inflamatorio. Se demuestran que los compuestos polifenólicos, especialmente los flavonoides, tienen propiedades antioxidantes que pueden utilizarse con fines terapéuticos en enfermedades como las crónico degenerativas. Estos resultados sugieren las perspectivas de futuros estudios para obtener una mejor comprensión de los componentes individuales y el uso de estos compuestos como un posible agente terapéutico para patologías como la inflamación y el aumento de radicales libres.

Palabras clave: Plantas medicinales; Actividad antiinflamatoria; Actividad antioxidante.

\section{Introdução}

As plantas medicinais são utilizadas pela população desde tempos imemoriais, representando uma fonte notável para o tratamento de diversas doenças humanas. São o foco da pesquisa moderna devido à sua grande diversidade química e biológica que pode fornecer substâncias com diversidade química e farmacológica (Wang et al., 2011; Yang et al., 2017), se tornando uma inspiração para o desenvolvimento de medicamentos (Newman; Cragg, 2012). A necessidade de novos agentes terapêuticos com maior eficácia e menos efeitos colaterais tem atraído grande atenção para as plantas medicinais por possuírem diversas atividades comprovadas (Ribeiro et al., 2018).

O interesse por medicamentos derivados de plantas (também conhecidos como medicamentos fitoterápicos) aumentou significativamente em todo o mundo (Dutra et al., 2016). As principais vantagens do uso de medicamentos fitoterápicos são o baixo custo, a acessibilidade e geralmente menos efeitos colaterais. Os estudos de pesquisa realizados em plantas medicinais são muito importantes para confirmar sua segurança e eficácia (Bhattacharya, 2017). Desde 2007, o Sistema Único de Saúde Pública do Brasil (SUS) oferece fitoterápicos derivados de plantas. Atualmente, o Ministério da Saúde (MS) disponibiliza a utilização de 13 medicamentos fitoterápicos na rede pública de saúde (Brasil, 2020). A necessidade urgente de novos agentes terapêuticos com maior eficácia e menos efeitos colaterais atraiu atenção às plantas medicinais para o tratamento de diversas patologias (Ribeiro et al., 2018).

Há uma grande incidência de doenças que envolvem o processo inflamatório e os medicamentos utilizados comumente para estas patologias apresentam diversos efeitos adversos. Isso tudo encoraja novas pesquisas em busca de substâncias que apresentem segurança e diminuam os efeitos nocivos dos processos inflamatórios. Dentro desse grupo de moléculas, as de origem natural vem ganhando destaque nos últimos anos (Guo et al., 2017).

A inflamação encontra-se no centro de muitas doenças comuns, incluindo artrite reumatoide, osteoartrite, aterosclerose, diabetes mellitus, neurodegeneração, infecção, alergia e câncer. Várias vias de sinalização formam uma rede pró-inflamatória e 
imunomoduladora, que assim definem a interação, os aspectos fisiológicos e fisiopatológicos da inflamação (Medzhitov, 2008). O processo inflamatório pode se desenvolver em resposta a uma invasão por um microrganismo ou por dano físico e é uma ação protetora crítica para lesões ou infecções, podendo apresentar os cinco sinais cardinais da inflamação (dor, calor, rubor, tumor e perda de função) (Salomé et al., 2020), sendo uma resposta fisiológica que protege nosso corpo contra danos nos tecidos ou micro-organismos. A reação inflamatória visa restaurar o tecido afetado pela lesão ou infecção (Ashley; Weil; Nelson, 2012).

Algumas classes de drogas já são descritas para tratamentos de doenças inflamatórias, como os anti-inflamatórios não esteroidais (AINEs) e corticosteroides, apresentando ações analgésicas, antipiréticas e anti-inflamatórias por agir inibindo a via das ciclo-oxigenases (COX) no mecanismo de dor, febre e inflamação. Porém, o uso prolongado desses medicamentos pode causar sérios efeitos colaterais além de serem de alto custo. Para doenças que apresentam um certo grau de complexidade como a inflamação, torna-se necessário a utilização de medicamentos que combatam múltiplos alvos se tornando mais eficazes, diminuindo os mecanismos compensatórios adversos (Harirforoosh, 2013).

Uma série de doenças pode ter seu risco reduzido pela ingestão de vários produtos à base de planta (Arasu et al., 2014). Em uma grande parte desses casos esses benefícios são atribuídos a alguns metabólitos secundários presentes nessas plantas que apresentam uma atividade antioxidante (Kim et al., 2014). As espécies reativas de Oxigênio (EROs) e radicais livres podem ser altamente prejudiciais e desempenham papeis importantes no envelhecimento e na patogênese de distúrbios relacionados à idade, como câncer, hipertensão, aterogênese, doença de Alzheimer e doença de Parkinson (Narayanasamy; Ragavan, 2012). Estilos de vida e hábitos alimentares pouco saudáveis podem aumentar intensamente a produção de EROs no corpo humano, o que pode criar um distúrbio entre a geração dessas espécies e as defesas antioxidantes do corpo, esse desequilíbrio é chamado de estresse oxidativo (El-Guezzane et al., 2021).

As EROs, como o oxigênio singlete $\left(\mathrm{O}_{2}\right)$, o ânion superóxido $\left(\mathrm{O}_{2}^{-}\right)$, o radical hidroxila $(\cdot \mathrm{OH})$ e o peróxido de hidrogênio $\left(\mathrm{H}_{2} \mathrm{O}_{2}\right)$ são frequentemente gerados como subprodutos de reações biológicas ou de fatores exógenos. Essas espécies reativas causam danos oxidativos em reações com quase todas as moléculas encontradas nas células vivas, incluindo o DNA. Assim, o excesso de EROs deve ser eliminado por um sistema antioxidante (De Vargas et al., 2016). Alguns antioxidantes naturais como a vitamina C e E são importantes por fazer a proteção contra essas espécies reativas de oxigênio (Arasu et al., 2015). A maioria dos metabólitos secundários com potencial antioxidante são compostos fenólicos, como os flavonoides e taninos (De Vargas et al., 2016).

Diante do exposto, o objetivo desse trabalho foi realizar um levantamento bibliográfico buscando as principais espécies medicinais da flora brasileira com potencial atividade anti-inflamatória e antioxidante e, dessa forma, colaborar no entendimento e importância dessas espécies vegetais como ferramentas promissoras a serem utilizadas na profilaxia e/ou tratamento das diversas condições fisiopatológicas que envolvam processos inflamatório e oxidativos.

\section{Metodologia}

Foi realizada uma revisão de literatura através das bases de dados PubMed, Science Direct e Scielo, onde procurou-se ampliar o âmbito da pesquisa, minimizando possíveis vieses nesta etapa do processo de elaboração da revisão. Para a escolha dos artigos, utilizou-se a pesquisa avançada e foram selecionados os seguintes descritores e suas combinações: "Brazilian medicinal plants", "anti-inflammatory activity" e "antioxidant activity" o cruzamento dos termos ocorreu com o marcador booleano "AND" assegurando a especificidade nas buscas. Os dados foram coletados em janeiro de 2021.

Quanto aos critérios de inclusão optou-se por: o período (últimos 10 anos), a língua (Inglês) e a originalidade. Foram utilizados como critérios de exclusão: artigos incompletos, artigos de revisão, repetidos, dissertações, teses e capítulos de livros. Foram excluídos também aqueles que o conteúdo não estivesse dentro do escopo da pesquisa. 


\section{Resultados e Discussão}

Após pesquisa nas bases de dados mencionadas anteriormente, foram identificados 1.185 artigos, dos quais 1.140 foram eliminados por não atenderem aos critérios de inclusão. Sendo assim, o total de 45 artigos publicados nos últimos 10 anos foram incluídos na presente revisão.

Para melhor compreensão e explanação do panorama de trabalhos encontrados, optou-se por categorizá-los de acordo com a utilização dos produtos naturais com atividade anti-inflamatória e atividade antioxidante. Sendo um total de 25 artigos com foco na atividade anti-inflamatória e 20 artigos com foco nas atividades antioxidantes.

\subsection{Atividade anti-inflamatória}

\subsubsection{Plantas medicinais com atividade anti-inflamatória}

Os artigos que foram contemplados na categoria de plantas medicinais do Brasil com atividade anti-inflamatório estão listados na Tabela 1 .

Tabela 1: Plantas medicinais com atividade anti-inflamatória.

\begin{tabular}{|c|c|c|}
\hline N. & Autor, Ano & Título do artigo \\
\hline 1 & Silva et al., 2020 & Spondias mombin: Quality control and anti-inflammatory activity in human neutrophils \\
\hline 2 & Alcântara et al., 2021 & $\begin{array}{l}\text { Confirmation of ethnopharmacological anti-inflammatory properties of Ocotea odorifera and } \\
\text { determination of its main active compounds }\end{array}$ \\
\hline 3 & Veras et al., 2021 & $\begin{array}{l}\text { The essential oil of the leaves of Verbesina macrophylla (Cass.) S.F.Blake has antimicrobial, } \\
\text { anti-inflammatory and antipyretic activities and is toxicologically safe }\end{array}$ \\
\hline 4 & $\begin{array}{l}\text { Quintans-Júnior et al., } \\
\qquad 2020\end{array}$ & $\begin{array}{l}\text { Dereplication and quantification of the ethanol extract of Miconia albicans (Melastomaceae) by } \\
\text { HPLC-DAD-ESI-/MS/MS, and assessment of its anti-hyperalgesic and anti-inflammatory } \\
\text { profiles in a mice arthritis-like model: Evidence for involvement of TNF- } \alpha \text {, IL-1 } \beta \text { and IL-6 }\end{array}$ \\
\hline
\end{tabular}

5 Kuraoka-Oliveira et al., Anti-inflammatory and anti-arthritic activity in extract from the leaves of Eriobotrya japonica 2020

\begin{tabular}{|c|c|c|}
\hline 6 & Stein et al., 2021 & $\begin{array}{l}\text { Chymase inhibition: A key factor in the anti-inflammatory activity of ethanolic extracts and } \\
\text { spilanthol isolated from Acmella oleracea }\end{array}$ \\
\hline 7 & Souza et al., 2021 & Toxicological and anti-inflammatory profile of Synadenium grantii Hook. f. in mice \\
\hline 8 & $\begin{array}{l}\text { Brandenburg et al., } \\
\qquad 2020\end{array}$ & $\begin{array}{l}\text { Baccharis dracunculifolia (Asteraceae) essential oil displays anti-inflammatory activity in } \\
\text { models of skin inflammation }\end{array}$ \\
\hline 9 & Lorençoni et al., 2020 & $\begin{array}{l}\text { Chemical composition and anti-inflammatory activity of essential oil and ethanolic extract of } \\
\text { Campomanesia phaea (O. Berg.) Landrum leaves }\end{array}$ \\
\hline 10 & Santos et al., 2021 & $\begin{array}{l}\text { Analgesic and anti-inflammatory articular effects of essential oil and camphor isolated from } \\
\text { Ocimum kilimandscharicum Gürke leaves }\end{array}$ \\
\hline
\end{tabular}




\section{Moraes et al., 2020 Antinociceptive and anti-inflammatory effect of Poincianella pyramidalis (Tul.) L.P. Queiroz}

12 Wound healing and anti-inflammatory activities induced by a Plantago australis hydroethanolic

12 Sperotto et al., 2018 extract standardized in verbascoside

\begin{tabular}{|c|c|c|}
\hline 13 & Aragão et al., 2017 & The anti-inflammatory and antinociceptive activity of albumins from Crotalaria retusa seeds \\
\hline 14 & Balin et al., 2018 & $\begin{array}{l}\text { Toxicological evaluation and anti-inflammatory potential of an ethanolic extract from Bromelia } \\
\text { balansae (Bromeliaceae) fruit }\end{array}$ \\
\hline 15 & Silva et al., 2017 & $\begin{array}{l}\text { Schinus terebinthifolius: phenolic constituents and in vitro antioxidant, antiproliferative and in } \\
\text { vivo anti-inflammatory activities }\end{array}$ \\
\hline 16 & Aquino et al., 2015 & $\begin{array}{l}\text { Anti-hyperalgesic and Anti-inflammatory Activity of Alternanthera maritima Extract and 2"-O- } \\
\alpha \text {-L-rhamnopyranosylvitexin in mice }\end{array}$ \\
\hline
\end{tabular}

17 Azevedo et al., 2016 Evidence of anti-inflammatory and antinociceptive activities of Plinia edulis leaf infusion

\begin{tabular}{|lll}
\hline 18 & Oliveira et al., 2019 & $\begin{array}{l}\text { Anti-inflammatory and antinociceptive properties of the hydroalcoholic fractions from the leaves } \\
\text { of Annona crassiflora Mart. in mice }\end{array}$ \\
\hline 19 & Silva, et al., 2015 & $\begin{array}{l}\text { Antinociceptive and anti-inflammatory activities of the ethanolic extract of Annona vepretorum } \\
\text { Mart. (Annonaceae) in rodents }\end{array}$ \\
\hline 20 & Muller et al., 2019 & $\begin{array}{l}\text { Lychnophora pinaster ethanolic extract and its chemical constituents ameliorate hyperuricemia } \\
\text { and related inflammation }\end{array}$ \\
\hline 21 & Carneiro et al., 2019 & $\begin{array}{l}\text { Sambucus australis Modulates Inflammatory Response via Inhibition of Nuclear Factor Kappa B } \\
\text { (NF-kB) in vitro }\end{array}$ \\
\hline 22 & Gusman et al., 2015 & $\begin{array}{l}\text { Evaluation of the Effects of Some Brazilian Medicinal Plants on the Production of TNF- } \alpha \text { and } \\
\text { CCL by THP-1 Cells }\end{array}$ \\
\hline 23 & Viscardi et al., 2017 & $\begin{array}{l}\text { Seed and peel essential oils obtained from Campomanesia adamantium fruit inhibit inflammatory } \\
\text { and pain parameters in rodents }\end{array}$ \\
\hline 24 & Boff et al., 2016 & $\begin{array}{l}\text { Strychnos pseudoquina A. St. Hil.: a Brazilian medicinal plant with promising in vitro anti-herpes } \\
\text { activity }\end{array}$ \\
\hline 25 & Barros et al, 2016 & $\begin{array}{l}\text { Pharmacological reports about gastroprotective effects of methanolic extract from leaves of } \\
\text { Solidago chilensis (Brazilian arnica) and its components quercitrin and afzelin in rodents }\end{array}$ \\
\hline
\end{tabular}

Fonte: Autores (2021).

O uso de plantas medicinais para tratar e controlar doenças, incluindo dores inflamatórias e corporais, que existem desde tempos imemoriais, está se tornando mais popular em todo o mundo (Komakech et al., 2019). Dentre os compostos ativos com atividades anti-inflamatórias e, extratos vegetais tem-se os compostos polifenólicos como flavonoides e proantocianidina, além de alcaloide, terpenoides e esteroides. Estes metabólitos secundários atuam em diferentes alvos envolvidos no processo inflamatório (Ribeiro et al., 2018).

O estudo conduzido por Aquino, et.al. (2015) demonstrou que o extrato de Alternanthera marítima é um agente antiinflamatório e anti-hiperalgésico. Sendo foi capaz de reduzir o edema de pata, reduzindo a migração de leucócitos e o extravasamento de proteína induzido por carragenina, além de inibir a hiperalgesia induzida pelo mesmo agente. Sendo o primeiro estudo a demonstrar que extratos dessa espécie exibem propriedades anti-inflamatórias. Todas essas ações são atribuídas pela inibição da nocicepção induzida por TNF- $\alpha$, mas outros mecanismos precisam ser investigados. 
Os experimentos in vivo, demonstraram que o extrato aquoso de Plinia edulis tem propriedades analgésicas significativas e reduz a inflamação, proporcionando assim suporte científico para o uso tradicional. Seus efeitos em camundongos foram semelhantes aos observados com o fármaco anti-inflamatório não esteroidal (AINEs) indometacina. Nesse estudo foram feitos testes de hipernocicepção inflamatória mecânica induzidos por carragenina, demonstrando que houve interferência na produção ou ações de citocinas que são relacionadas com os mecanismos terapêuticos desta espécie. Também demonstrou que o tratamento com $300 \mathrm{mg} / \mathrm{kg}$ deste extrato reduziu contorções abdominais, mecanismo esse relacionado com a diminuição de biossíntese de prostaglandinas, houve também a redução da migração de leucócitos para a cavidade intraperitoneal, comprovando que o extrato possui substâncias com ação anti-inflamatórias eficazes (Azevedo et. al., 2016).

Annona crassiflora Mart., popularmente conhecida por Araticum é utilizada para doenças inflamatórias e dolorosas, como feridas, picadas de cobra, diarréias, malária e reumatismo. Demonstrou-se também efeitos anti-inflamatórios e antinociceptivos a partir do filtrado de frações hidroalcóolicas obtidas das folhas de Annona crassiflora Mart. No teste de nocicepção induzida por formalina as frações hidroalcóolicas induziu antinocicepção significativa apenas na segunda fase do teste, correspondendo a dor inflamatória, sugerindo que o efeito antinociceptivo pode ser devido a uma ação antiinflamatória pela inibição da síntese ou ação de mediadores inflamatórios, já na administração intratorácica de carragenina houve uma inibição parcial do recrutamento de neutrófilos, além de abolir a migração de neutrófilos induzida por LPS. Esses resultados exibem uma contribuição potencial no tratamento de dores e doenças inflamatórias (Oliveira et. al., 2019).

O extrato de Annona vepretorum tem em sua composição compostos do grupo dos fenólicos, dos esteroides, dos terpenoides e dos flavonoides. Foram demonstradas propriedades antinociceptivas e anti-inflamatórias significativas relacionadas provavelmente com a ativação de receptores opioides e inibição da liberação de mediadores do processo inflamatório como prostaglandinas, histamina e neutrófilos (Silva et al., 2015).

O extrato etanólico de Lychnophora pinaster demonstrou efeito promissor na terapia da gota. O extrato reduziu os níveis séricos de ácido úrico em camundongos hiperuricêmicos, bem como inibiu a atividade hepática de XOD (enzima do metabolismo da purina, responsável por catalisar a oxidação da xantina em ácido úrico), apresentando também uma atividade anti-inflamatória, promovendo redução do edema semelhante ao obtido para o fármaco padrão indometacina em 24, 48 e 72 horas, sendo essa uma atividade relatada pela primeira vez na literatura e apresentando resultados semelhantes aos obtidos para os fármacos usados na terapia da doença, como o alopurinol e a indometacina (Muller et. al., 2019).

Carneiro e colaboradores (2019) concluíram que Sambucus australis possui atividade anti-inflamatória potencial in vitro, levando a uma redução dos níveis de citocinas Th2, incluindo IL-4 e IL-5 e aumento dos níveis da citocina reguladora IL10, desempenhando um papel protetor no processo inflamatório. Todos esses mecanismos foram confirmados ao observar que houve uma diminuição da expressão do fator de transcrição NF-kB, que é responsável por regular a transcrição desses fatores pró-inflamatórios.

Os extratos de Caryocar brasiliensis, Casearia sylvestris, Coccoloba cereifera e Terminalia glabrescens inibiram a produção de TNF- $\alpha$ de forma dependente da concentração $(62,5125$ e $250 \mu \mathrm{g} / \mathrm{mL})$ em estudo conduzido por Gusman, et. al. (2015). O fracionamento destes extratos potencializou o efeito anti-TNF- $\alpha$, que se mostrou concentrado em frações polares, compostas principalmente por polifenóis. Os resultados permitiram identificar extratos com capacidade seletiva de bloqueio produção de citocinas (Gusman et al., 2015).

Dados experimentais demonstraram que os óleos essenciais da casca e da semente de frutos de Campomanesia adamantium exibiram efeitos contra a migração de leucócitos induzida por carragenina na pleura mostrando que os óleos contêm compostos com ação anti-inflamatória. Além disso, seu uso pode ser considerado seguro porque não causou nenhuma 
mortalidade ou alterações no comportamento geral de ratos em estudos de toxicidade aguda, sugerindo, assim, seu potencial uso como nutracêutico ou agente farmacológico (Viscardi et. al., 2017).

Os resultados obtidos por Boff et. al (2016) indicaram que as amostras do extrato padronizado do caule de Strychnos pseudoquina e dois de seus compostos isolados (éter de quercetina 3-O-metílico e estricnobiflavona) apresentam atividades antiherpes e anti-inflamatória. A atividade anti-inflamatória ocorre pela inibição da liberação de proteína quimioatrativa de monócitos - 1 (MCP-1) por células TH1 estimuladas por LPS. O que é uma característica interessante, uma vez que o resfriado e as feridas genitais são acompanhados por um processo de inflamação (Boff et. al., 2016).

Barros e colaboradores (2016) verificaram que após 4 dias de administração oral de extrato metanólico de Solidaco chilensis $(100 \mathrm{mg} / \mathrm{kg}$ ), popularmente conhecida como arnica, a área da úlcera gástrica induzida por ácido acético foi reduzida e a regeneração da mucosa gástrica foi acompanhada por uma redução nos níveis de TNF- $\alpha$ gástrico. As propriedades curativas do extrato também foram confirmadas pelo aumento da proliferação e cobertura de feridas arranhadas em monocamada de fibroblasto. Esses resultados confirmaram o efeito gastroprotetor de extrato metanólico de Solidaco chilensis, bem como seu potencial de cura e forneceu suporte para o uso tradicional dessa espécie vegetal para prevenção e tratamento de leões no estômago (Barros et. al., 2016).

A espécie Spondias mombin L., uma árvore conhecida como "cajazeira” no Nordeste do Brasil, além de seus frutos, suas folhas são bastante utilizadas na medicina tradicional por suas propriedades anti-inflamatórias, antimicrobianas e antivirais. Estudos mostraram que o extrato foi capaz de modular a ativação de neutrófilos, determinada pela redução da liberação da enzima mieloperoxidase pelos neutrófilos, o que pode desempenhar um papel importante na atividade anti-inflamatória in vivo da espécie (Silva et al., 2020).

Estudos com Ocotea odorifera (Vell.) Rohwer, planta muito utilizada na medicina tradicional no sul do Brasil para o tratamento de doenças relacionadas à inflamação, mostraram que diferentes frações de seu extrato etanólico demonstraram atividade anti-inflamatória por dupla inibição do edema e recrutamento de neutrófilos (Alcântara et al., 2021).

O óleo essencial de Verbesina macrophylla (Cass.) SFBlake, uma planta medicinal da América do Sul, popularmente conhecida como "asa de peixe", "asa de peixe branco", "cambará branco" ou "cambará guaçu", demonstrou atividade antiinflamatória reduzindo os níveis das citocinas pró-inflamatórias TNF- $\alpha$ e IL-1 $\beta$, e edema de orelha nas concentrações de 4 , 40 e $400 \mathrm{mg} / \mathrm{kg}$. A atividade antipirética apresentada pelo óleo essencial é estatisticamente semelhante à dipirona (Veras et al., 2021).

No Nordeste do Brasil, a planta Miconia albicans (Sw) Triana (Melastomataceae), tem sido utilizada no tratamento de doenças inflamatórias crônicas, como artrite reumatoide (AR) e outras doenças articulares. Estudos apontaram que o extrato etanólico da folha de M. albicans, reduziu significativamente a migração de leucócitos no modelo de pleurisia e reduziu os níveis de TNF- $\alpha$ e IL-1 $\beta$ na lavagem pleural, diminuindo a ação inflamatória. E no modelo animal reduziu significativamente os comportamentos nociceptivo e hiperalgésico (Quintans-Júnior et al., 2020).

A Eriobotrya japonica é uma planta medicinal chinesa que atualmente é cultivada no Brasil. A infusão de suas folhas é tradicionalmente usada no tratamento de inflamações. Nos estudos, A E. japonica apresentou atividade anti-inflamatória no modelo de pleurisia, inibindo a migração de leucócitos, extravasamento de proteínas e produção de óxido nítrico (KuraokaOliveira et al., 2020).

Acmella oleracea (L.) RK Jansen (Asteraceae), conhecida como jambu no Brasil, é amplamente utilizada na medicina tradicional como analgésico e para quadros inflamatórios, caracterizada pela presença de $\mathrm{N}$-alquilamidas, principalmente espilantol. Sua atividade foi comprovada através da administração de extratos ou espilantol, que inibiu significativamente a formação de edema, produção de Óxido Nítrico (NO) e infiltração do tecido celular no teste da formalina, sem causar toxicidade renal e hepática (Stein et al., 2021). 
Synadenium grantii Hook. f., popularmente conhecida como "janaúba" ou "leiterinha", é utilizada na medicina tradicional no tratamento de doenças estomacais, certos tipos de câncer e doenças inflamatórias. A análise do exsudato inflamatório de camundongos tratados com S. grantii mostrou redução na migração de células polimorfonucleares (PMNs) para o tecido inflamado, bem como redução nas citocinas pró-inflamatórias TNF- $\alpha$ e IL-1 $\beta$ (Souza et al., 2021).

A Baccharis dracunculifolia (Asteraceae) é uma planta comumente usada na medicina tradicional conhecida como "alecrim do campo". É amplamente utilizado, entre outros, como um imunoestimulante, antibiótico, agente anti-inflamatório. O tratamento tópico com óleo essencial de B. dracunculifolia suprimiu parâmetros inflamatórios em modelos de dermatite aguda e crônica. Esse efeito protetor foi associado à redução da formação de edema, menor influxo de células no tecido inflamado e redução da hiperproliferação de queratinócitos (Brandenburg et al., 2020).

As espécies de campomanesia, que são usadas na medicina popular para fins anti-inflamatórios, anti-ulcerogênicos, antidiabéticos, anti-obesitários, entre outros. Em estudos, tanto óleo essencial quanto o extrato etanólico inibiram a produção de ânion superóxido $\left(\mathrm{O}_{2}{ }^{\bullet}\right)$, óxido nítrico intracelular e citocinas pró-inflamatórias IL-6, e TNF- $\alpha$ na concentração. Além disso, a inibição do NF-kB foi observada (Lorençoni et al., 2020).

As folhas de Ocimum kilimandscharicum Gürke (Lamiaceae) são popularmente usadas contra a dor articular. O tratamento com o seu óleo essencial inibiu significativamente o edema induzido por carragenina, hiperalgesia mecânica e fria. Ambos, o óleo essencial de $O$. kilimandscharicum e a cânfora inibiram significativamente a rolagem de leucócitos induzida por carragenina e a adesão, confirmando sua capacidade anti-inflamatória, contribuindo, pelo menos em parte, para explicar o uso popular das folhas de O. kilimandscharicum contra a dor (Santos et al., 2021).

Poncianella pyramidalis (Leguminosae) é uma planta da Caatinga utilizada na medicina popular devido às suas propriedades farmacológicas, que incluem ação anti-inflamatória. Os estudos com Poncianella pyramidalis apontaram a inibição do o extravasamento de proteínas, aumentando leucócitos e neutrófilos totais e inibindo células mononucleares. O efeito antioxidante in vitro, bem como atividades antinociceptiva e anti-inflamatória in vivo, pode ser atribuído ao fato da casca ser rica em compostos fenólicos derivados do ácido gálico (Moraes et al., 2020).

Plantago australis é uma planta popular amplamente difundida na América Latina. Na medicina popular, as sementes e folhas são utilizadas, como anti-inflamatórios, cicatrização de feridas, entre outros. Estudos sugerem que o extrato hidroetanólico de $P$. australis (PAHE) e o verbascosídeo induziram aumento significativo na migração dos queratinócitos. A atividade de cicatrização de feridas in vivo mostrou que a PAHE acelerou o processo. Os tratamentos com PAHE e verbascosídeo induzem aumento nas enzimas antioxidantes, sugerindo uma possível ativação dessas enzimas. Em células ativadas por LPS, o verbascosídeo exibiu uma redução significativa de TNF- $\alpha$, IL-6, IL-12p70, MCP-1 e INF $\gamma$, enquanto o PAHE exibiu apenas redução estatisticamente significativa em TNF- $\alpha$. Curiosamente, ambos os compostos podem reduzir os parâmetros oxidativos em células N9 ativadas por LPS. Além disso, o pré-tratamento com PAHE inibiu o edema da pata em ratos (Sperotto et al., 2018).

As sementes de Crotalaria retusa L. são utilizadas na medicina popular devido às suas propriedades farmacológicas e, em especial, a fração de albumina obtida de suas sementes contém lectina, proteína conhecida pela atividade analgésica e antiinflamatória. Assim, albuminas extraídas de C. retusa foram estudadas por seus efeitos anti-inflamatórios e antinociceptivos. Os dados mostraram que as sementes de C. retusa possuem propriedades anti-inflamatórias e antinociceptivas e tais atividades provavelmente se devem ao efeito inibitório da migração de neutrófilos da lectina presente nas albuminas (Aragão et al., 2017)

Bromelia balansae é uma espécie medicinal relativamente inexplorada, usada para fins nutricionais e na medicina popular para tratar tosse ou feridas. Estudos apontam que o extrato etanólico obtido da fruta Bromelia balansae (EEBB) reduziu significativamente a formação de edema, hipersensibilidade mecânica induzida por carragenina e sensibilidade ao frio, bem como a migração de leucócitos no modelo de pleurisia (Balin et al., 2018). 


\subsubsection{Constituintes químicos responsáveis pela atividade anti-inflamatória}

Os flavonoides são compostos amplamente distribuídos entre plantas e bastante estudados por exibir diversos efeitos farmacológicos, dentre eles no processo inflamatório. A presença de flavonoides no extrato de A. Maritima está amplamente associada com o uso desta espécie como agente anti-inflamatório, estudos sugerem que 2"-O- $\alpha$-L-ramnopiranosylvitexina foi o responsável pelos efeitos encontrados na referida espécie. (Aquino et al., 2015). Os flavonoides também são componentes da fração hidroalcoólica das folhas de Annona crassifora, sendo eles: epicatequina e dois glicosídeos de quercetina, sugerindo sua atuação nas vias da lipoxigenase e da ciclooxigenase, inibindo a produção de mediadores inflamatórios, incluindo LTB4 (Oliveira et. al., 2019). Os flavonoides vitexina e rutina presentes no extrato etanólico de Lychnophora pinaster também são relatados na literatura por reduzir os níveis de ácido úrico podendo ser utilizados na terapia da gota (Muller et. al., 2019). Os flavonoides éter de quercetina 3-O-metílico (3MQ) e estricnobiflavona isolados do caula da espécie Strychnos pseudoquina apresentaram atividades anti-inflamatórias, demonstrando que a combinação de terapia antiviral com agentes anti-inflamatórios parece ser uma estratégia benéfica para o controle de infecções por herpes-vírus simples (Boff et. al., 2016).

A quercitrina é um flavonoide comum presente em várias plantas do gênero Solidago, incluindo S. chilensis. No entanto, o afzelin, até onde sabemos, ainda não tinha sido relatada anteriormente para esta espécie, embora sua presença tenha sido evidenciada em outras, como $S$. canadensis. A participação da quercitrina e da afzelina no efeito gastroprotetor do extrato de $S$. chilensis foi confirmada e estão relacionadas às suas propriedades antioxidantes e anti-secretoras em paralelo ao seu efeito benéfico na produção de muco, subsidiando o uso tradicional da espécie para prevenção e tratamento de lesões gástricas (Barros et. al., 2016).

Após análise do extrato etanólico de Miconia albicans por HPLC-DAD, a presença de rutina foi verificada, sendo um bioflavonoide escolhida como marcador analítico deste extrato, por apresentar efeito antiartrítico, inibindo o processo inflamatório em suas fases aguda e crônica e diminuindo a artrite reumatoide por inibir a superprodução de radicais de oxigênio.

É bem conhecido que os compostos fenólicos apresentam atividades antitumoral, antinociceptiva e anti-inflamatória fortemente associadas à sua atividade antioxidante e ao conteúdo de fenol. Além disso, existe uma correlação positiva bem estabelecida entre os fenólicos totais de uma determinada amostra e sua atividade antioxidante. Os compostos fenólicos são importantes devido às suas estruturas químicas, ideais para sequestro e neutralização de radicais (Moraes et al., 2020). Compostos fenólicos foram encontrados ao realizar o perfil cromatográfico de folhas de Spondias mombin, onde foi possível identificar e quantificar pela primeira vez o marcador bioativo geraniína, bem como a presença de outros compostos, como o ácido clorogênico que são responsáveis pela grande parte da sua atividade anti-inflamatória (Silva et al., 2020).

O perfil fitoquímico da espécie Poncianella pyramidalis mostrou que a fração é rica em compostos polifenólicos, principalmente derivados dos ácidos gálico e elágico. O pico principal foi reconhecido como ácido 3,3'-dimetoxielágico-4'-O- $\beta$ D-glucopiranosídeo. Outros constituintes principais foram o éter 3,4-dimetílico do ácido gálico, o ácido elágico e o éter 3metílico do ácido elágico, apresentando atividades antioxidantes, neuroprotetoras, antivirais, antimicrobianas, antidiabéticas, anti-apoptóticas, anti-inflamatórias, antinociceptivas e antitumorais (Moraes et al., 2020).

Estudos sobre a composição fitoquímica de Plantago australis demonstraram a presença de metabólitos secundários que exibem atividade biológica, incluindo compostos fenólicos, como o verbascosídeo. Estruturalmente, este composto é caracterizado por quatro grupos químicos: um ácido caféico, 4,5-hidroxifeniletanol ligado a um $\beta$ - (D) - glucopiranosídeo, um agrupamento ramnose e uma molécula de glicose. Este composto é conhecido por possuir diversas atividades farmacológicas, como antioxidante, anti-inflamatório, cicatrizante e antinociceptivo (Sperotto et al., 2018).

Uma outra classe bem relacionada com atividade anti-inflamatória são os terpenoides, suas propriedades antiinflamatórias compreende a interação com importantes enzimas da cascata da inflamação, como a fosfolipase A2 (PLA2), ciclooxigenase (COX) e lipoxigenase (LOX). Os ácidos oleanólico e ursólico (triterpenos), presentes no extrato aquoso de Plinia 
edulis, promoveram ações antinociceptivas e antialodínicas in vivo, provavelmente pela modulação de nociceptores e inibição da liberação de mediadores pró-inflamatórios e apresentaram efeito anti-inflamatório por meio da inibição de enzimas e mediadores pró-inflamatórios, supressão da expressão de genes pró-inflamatórios e regulação das células inflamatórias relacionadas (Azevedo et. al., 2016). Esses mesmos constituintes foram isolados na espécie Eriobotrya japonica, sendo responsável pelo seu efeito anti-inflamatório (Kuraoka-Oliveira et al., 2020). O ácido ursólico é relatado na literatura por apresentar atividade anti-inflamatória relacionada a espécie Sambucus australis, possuindo, além desta, outras atividades relacionadas ao seu uso como antitumoral, antioxidante, antibacteriana e hipoglicêmica (Carneiro et.al., 2019).

Conforme indicado na literatura, os sesquiterpenos são compostos de ocorrência natural com uma diversidade de usos medicinais relatados, como, entre outros, os anti-inflamatórios. A extração do óleo essencial de Verbesina macrophylla por hidrodestilação (HD) apresentou sua composição constituída principalmente por sesquiterpenos com os principais componentes sendo germacreno D, germacreno D-4-ol, biciclogermacreno, (E) -cariofileno e $\delta$-cadineno. Esses sesquiterpenos foram encontrados em óleos de várias espécies apontando para uma possível assinatura fitoquímica do gênero, podendo ser responsáveis pelas atividades anti-inflamatórias observadas.

Brandenburg e colaboradores (2020) evidenciaram que a maioria da composição do óleo essencial obtido das folhas de Baccharis dracunculifolia são sesquiterpenos, principalmente limoneno, $\beta$-cariofileno, biciclogermacreno e nerolidol, a presença desses compostos pode ser a principal explicação para a importante atividade anti-inflamatória e antiproliferativa descrita.

Da espécie Bromelia balansae foram identificados 35 compostos extraídos do óleo essencial dos seus frutos, sendo os sesquiterpenos a classe mais abundante detectada. Além deles também foram isolados quatro flavonóis de glicosídeo (kaempferol-3-O- $\alpha$-1-ramnopiranosídeo, kaempferol-3-O- $\alpha$-lrhamnopiranosil- $(1 \rightarrow 6)$ - $\beta$-d-glucopiranosídeo, quercetina3-O- $\alpha$ 1- rhamnopiranosil- ( $1 \rightarrow 6$ ) - $\beta$-d-glucopiranosídeo e kaempferol 3,7-di-Oal-ramnopiranosídeo) no extrato metanólico de frutos de B. balansae. Esses flavonóis glicosídeos naturais estão entre os polifenóis mais importantes na dieta humana devido às suas diversas propriedades benéficas, incluindo atividades antioxidantes, antidiabetes e anti-inflamatórias.

O efeito anti-inflamatório apresentado pelo extrato de Synadenium grantii relaciona-se à presença de um éster diterpeno forbol, o 3,4,12,13-tetraacetilforbol-20-fenilacetato, sendo o principal componente previamente isolado. Além disso, esta espécie também conta com a presenta de flavonoides e compostos fenólicos, não podendo descartar a sua participação no efeito antiinflamatório relatado (Souza et al., 2021).

Os principais constituintes do óleo essencial das folhas de Campomanesia phaea foram os terpenoides (E) -cariofileno, óxido de cariofileno, $\alpha$-selinen, $\gamma$-muuroleno, $\delta$-cadineno, $\alpha$-copaeno, $\beta$-selineno, linalol e alo-aromadendreno, sendo relacionados com as atividades anti-inflamatórias relatadas pela medicina popular ao utilizar o óleo essencial desta espécie (Lorençoni et al., 2020).

Do extrato etanólico de Lychnophora pinaster foi possível identificar os seguintes compostos: ácidos cafeico, clorogênico, cinâmico e rutina, lupeol e estigmasterol e devem ser considerados como agentes promissores na terapia da gota e o ácido E-licnofórico foi o composto que apresentou melhor atividade anti-inflamatória (Muller et. al., 2019).

Os óleos essenciais extraídos da casca da espécie Campomanesia adamantium também apresentaram atividades antiinflamatórias satisfatórias, do referido óleo foram obtidos os compostos limoneno, tujopseno e $\beta$-pineno que podem ser caracterizados como contribuintes para os efeitos anti-inflamatórios e antinociceptivos (Viscardi et. al., 2017).

A espécie Ocotea odorifera é relatada pela sua grande produção de diferentes metabólitos secundários, obtidos de suas diferentes partes. Dentre eles pode citar os óleos essenciais que são isolados de diversas partes aromáticas desta planta. O óleo essencial obtido a partir de suas folhas caracteriza-se pela presença de safrol, cânfora e biciclogermacreno, este último é um sesquiterpeno já bem relatado por usa atividade anti-inflamatória. Além disso, sabe-se que a cânfora também apresenta várias propriedades biológicas, inclusive anti-inflamatórias. Os alcaloides são uma classe de substâncias comumente encontradas no 
gênero Ocotea e são potencialmente anti-inflamatórios, uma dessas substâncias foi identificada como o alcaloide S -(+)reticulina, que foi relatado por apresentar atividade anti-inflamatória (Alcântara et al., 2021).

A cânfora é o principal constituinte do óleo essencial de Ocimum kilimandscharicum e foi cientificamente estudada por suas propriedades analgésicas, antiedematogênicas e cardiovasculares. Outros constituintes deste óleo, como 1,8-cineol, pineno e limoneno também mostraram atividade anti-inflamatória (Santos et al., 2021).

\subsection{Atividade antioxidante}

\subsubsection{Plantas medicinais com atividade antioxidante}

Os artigos que foram contemplados na categoria de plantas medicinais do Brasil com atividade antioxidante estão apresentados na Tabela 2, a seguir.

Tabela 2: Plantas medicinais com atividade antioxidante.

\begin{tabular}{|c|c|c|}
\hline N. & Autor/Ano & Título do artigo \\
\hline 1 & Pereira et al., 2020 & $\begin{array}{l}\text { Evaluation of the chemical composition and antioxidant activity of extracts and fractions of Ocotea } \\
\text { notata (Ness) Mez (Lauraceae) }\end{array}$ \\
\hline 2 & Teles et al., 2021 & $\begin{array}{l}\text { Aniba rosaeodora (Var. amazonica Ducke) Essential Oil: Chemical Composition, Antibacterial, } \\
\text { Antioxidant and Antitrypanosomal Activity }\end{array}$ \\
\hline 3 & Lima Júnior et al., 2021 & $\begin{array}{l}\text { Anacardium humile St. Hil as a novel source of antioxidant, antiglycation and } \alpha \text {-amylase inhibitors } \\
\text { molecules with potential for management of oxidative stress and diabetes }\end{array}$ \\
\hline 4 & Aquino et al., 2020 & $\begin{array}{l}\text { Investigation of the antioxidant and hypoglycemiant properties of Alibertia edulis (L.C. Rich.) A.C. } \\
\text { Rich. leaves }\end{array}$ \\
\hline 5 & Baldivia et al., 2018 & $\begin{array}{l}\text { Evaluation of In Vitro Antioxidant and Anticancer Properties of the Aqueous Extract from the Stem } \\
\text { Bark of Stryphnodendron adstringens }\end{array}$ \\
\hline 6 & Morais et al., 2016 & $\begin{array}{l}\text { Phytochemical screening and antioxidant potencial evaluation of Cnidoscolus phyllacanthus (Müll. } \\
\text { Arg.) Pax \& K. Hoffm from Apodi - RN }\end{array}$ \\
\hline 7 & Rocha et al., 2019 & $\begin{array}{l}\text { Microbiological quality, chemical profile as well as antioxidant and antidiabetic activities of Schinus } \\
\text { terebinthifolius Raddi }\end{array}$ \\
\hline 8 & Salgueiro et al., 2016. & In vitro and in silico antioxidant and toxicological activities of Achyrocline satureioides \\
\hline 9 & Franco et al., 2020 & $\begin{array}{l}\text { Antidiabetic potential of Bauhinia forficata Link leaves: a non-cytotoxic source of lipase and glycoside } \\
\text { hydrolases inhibitors and molecules with antioxidant and antiglycation properties }\end{array}$ \\
\hline 10 & Oliveira et al., 2017 & $\begin{array}{l}\text { The ethanol extract of Leonurus sibiricus L. induces antioxidant, antinociceptive and topical anti- } \\
\text { inflammatory effects }\end{array}$ \\
\hline 11 & Silva et al., 2017 & $\begin{array}{l}\text { New aspects on the hepatoprotective potential associated with the antioxidant, hypocholesterolemic } \\
\text { and anti-inflammatory activities of Vernonia condensata Baker }\end{array}$ \\
\hline 12 & Ascari et al., 2019 & $\begin{array}{l}\text { Chemical composition, antioxidant and anti-inflammatory activities of the essential oils from male and } \\
\text { female specimens of Baccharis punctulata (Asteraceae) }\end{array}$ \\
\hline 13 & Lopes Neto et al., 2017 & $\begin{array}{l}\text { Impact of bioaccessibility and bioavailability of phenolic compounds in biological systems upon the } \\
\text { antioxidant activity of the ethanolic extract of Triplaris gardneriana seeds }\end{array}$ \\
\hline 14 & Cesário et al., 2018 & $\begin{array}{l}\text { Evaluation of the antioxidant and gastroprotective activity and HPLC analysis of the hydroalcoholic } \\
\text { extract of Tocoyena formosa leaves (Cham. \& Schlecht) K. Schum }\end{array}$ \\
\hline 15 & Nascimento et al., 2018 & $\begin{array}{l}\text { HPLC and in vitro evaluation of antioxidant properties of fruit from Malpighia glabra (Malpighiaceae) } \\
\text { at different stages of maturation }\end{array}$ \\
\hline
\end{tabular}




\begin{tabular}{|c|c|c|}
\hline 16 & Pedroso et al., 2017 & $\begin{array}{l}\text { Chemical constituents of Cochlospermum regium (Schrank) Pilg. root and its antioxidant, antidiabetic, } \\
\text { antiglycation, and anticholinesterase effects in Wistar rats }\end{array}$ \\
\hline 17 & Cabral et al., 2016 & Phytochemical study and anti-inflammatory and antioxidant potential of Spondias mombin leaves \\
\hline 18 & Lima et al., 2017 & $\begin{array}{l}\text { Hypolipemiant and antioxidant effects of Eugenia brasiliensis in an animal model of coconut oil- } \\
\text { induced hypertriglyceridemia }\end{array}$ \\
\hline 19 & Justino et al., 2018 & $\begin{array}{l}\text { Annona muricata Linn. leaf as a source of antioxidant compounds with in vitro antidiabetic and } \\
\text { inhibitory potential against } \alpha \text {-amylase, } \alpha \text {-glucosidase, lipase, non-enzymatic glycation and lipid } \\
\text { peroxidation }\end{array}$ \\
\hline 20 & Veras et al., 2020 & $\begin{array}{l}\text { Chemical composition and evaluation of the antinociceptive, antioxidant and antimicrobial effects of } \\
\text { essential oil from Hymenaea cangaceira (Pinto, Mansano \& Azevedo) native to Brazil: A natural } \\
\text { medicine }\end{array}$ \\
\hline
\end{tabular}

Fonte: Autores (2021).

A busca por plantas medicinais com propriedades químicas bioativas para o desenvolvimento de novos fármacos com diversas finalidades terapêuticas tem se intensificado nos últimos anos, uma vez que os alguns medicamentos disponíveis para consumo possuem importantes efeitos adversos e por apresentarem, em alguns casos, um índice de resistência. Além disso, a maioria dos medicamentos usados atualmente apresentam etapas de desenvolvimento e produção muito dispendiosas. Portanto, há grande interesse na descoberta e identificação de compostos eficazes com baixos custos de produção e alta seletividade de células-alvo e que venha a servir de base no desenvolvimento de novos medicamentos (Carvalho et al., 2019).

A inflamação pode ser apontada como um fator no processo de carcinogênese e expressar processos de envelhecimento, de modo que o processo inflamatório induz estresse oxidativo e reduz a capacidade antioxidante. Dessa forma, a capacidade antioxidante associada a um efeito anti-inflamatório são características desejáveis para um composto bioativo (Cabral et al., 2016). Numerosos estudos avaliaram o potencial antioxidante de extratos de diferentes plantas que são encontradas na fauna brasileira.

A Ocotea notata (Nees \& Mart). Mez pertencente à família Lauraceae, é conhecida como "canela branca", podendo ser encontrada em regiões de restinga do litoral brasileiro, apresentou atividade antioxidante por diferentes métodos. $\mathrm{O}$ extrato, partições e subfrações testadas pelo método DPPH (2,2-difenil-1-picril-hidrazil) apresentaram potencial antioxidante relevante quando comparados ao extrato de Ginkgo biloba (controle). Para o método ORAC (Oxygen Radical Absorbance Capacity), a partição de acetato de etila apresentou características anti-oxidantes melhores que o obtido em Ginkgo biloba. Ademais, também demonstrou que as frações com a mistura de flavonoides têm um potencial antioxidante superior quando comparadas aos flavonoides isolados, sugerindo um efeito sinérgico (Pereira et al., 2020). Aniba rosaeodora (Var. Amazonica Ducke), pertencente à família Lauraceae é uma árvore de grande porte que atinge $30 \mathrm{~m}$ de altura, com casca amarelo-acastanhada que cresce na região amazônica. O óleo essencial extraído desta espécie é muito utilizado na indústria de perfumaria e apresentou atividade antioxidante significativa que corroborou com estudos anteriores de espécies de Aniba (Teles et al., 2021).

Anacardium humile St. Hil (Anacardiaceae), popularmente conhecido como Cajuí ou Cajuzinho-do-Cerrado, é uma planta típica da savana brasileira usada na medicina tradicional por sua capacidade anti-inflamatória, anticâncer, antidiarreica e antidiabética. Neste estudo, a sua atividade antioxidante também foi comprovada e a análise mostrou atividade antioxidante relevante da fase dicloromenato e etanólica, além das moléculas isoladas, principalmente ácido gálico pelos métodos DPPH, ORAC e FRAP (Ferric Reducing Antioxidant Power), comprovando a atividade antioxidante, anti-inflamatória e antidiabética do ácido gálico (Lima Júnior et al., 2021).

Alibertia edulis (Família Rubiaceae) é uma planta popularmente conhecida na América do Sul como "marmelo-bola" ou "marmelo do cerrado". Seu uso popular se dá através do chá de suas folhas, principalmente para o controle do diabetes. 
Estudos feitos com esta espécie, justificaram em parte o seu uso popular, onde os extratos das folhas confirmam considerável suporte ao sistema antioxidante, interferindo na expressão das enzimas superóxido dismutase (SOD) e catalase e inibiu a fosforilação do receptor IKK (que confere resistência à insulina), sugerindo que o poder hipoglicemiante observado pode estar relacionado ao seu conhecido potencial antioxidante, protegendo efetivamente contra a hemólise e exercendo uma nítida atividade hipoglicemiante in vivo, indicando que nas concentrações comumente consumidas, o extrato não é tóxico para as células normais (Aquino et al., 2020).

Stryphnodendron adstringens (Mart.) Coville (Fabaceae) é uma espécie encontrada no Cerrado brasileiro, comumente conhecida como barbatimão ou casca-da-mocidade, que apresenta potencial para o desenvolvimento de novos fármacos considerando sua composição química e atividades biológicas previamente descritas na literatura. Na medicina tradicional, as decocções ou infusões da casca do caule desta planta são utilizadas para tratar problemas de próstata, doenças hepáticas e cutâneas, má circulação, feridas, infecções fúngicas, inflamação dentária, gastrite e diabetes. O extrato aquoso de S. adstringens mostrou alta concentração de compostos fenólicos com atividades antioxidantes e efeito anticâncer. O seu extrato aquoso também protegeu os eritrócitos humanos contra os danos causados pelo agente antioxidante 2'- azobis (2- metilpropanimidamida) (AAPH), resultando na inibição da hemólise oxidativa e na redução dos níveis de malondialdeído (MDA) (Baldivia et al., 2018).

Outra espécie do Cerrado Brasileiro é a Bauhinia forficata Link, pertencente à família Fabaceae. O uso das suas folhas é estimulado pelo Sistema Único de Saúde (SUS) como tratamento complementar para o Diabetes Mellitus tipo 2, pois diversos estudos apontam essa planta como antidiabética. O tratamento com B. forficata reduziu a concentração de malondialdeído (MDA), que é um importante biomarcador utilizado na avaliação do estresse oxidativos, sem interferir na atividade da enzima catalase (enzima antioxidante), esta capacidade antioxidante é atribuída ao conteúdo de flavonoides (por exemplo, kaempferol e quercetina) (Franco et al., 2020).

Cnidoscolus phyllacanthus (Müll. Arg.) Pax \& L. Hoffm., popularmente conhecida como faveleira ou favela, é uma espécie pertencente à família Euphorbiaceae e endêmica da caatinga nordestina, que ocorre abundantemente em diversos Estados do Brasil, com destaque na Paraíba, Pernambuco, Bahia, Piauí, Rio Grande do Norte, Ceará, Sergipe e Alagoas. Na medicina popular são relatadas, principalmente, as propriedades: cicatrizante, analgésica, anti-inflamatória, antibiótica e diurética. A avaliação da capacidade antioxidante dos extratos da C. phyllacanthus, foi feito através do método de captura dos radicais livres DPPH, onde demonstrou que o extrato hexânico das folhas que apresentou uma relevante atividade antioxidante semelhante ao obtido com o padrão positivo vitamina C. Identificando um expressivo potencial antioxidante apenas nas folhas do vegetal, análise esta que pode servir de base para estudos futuros que busquem novas fontes naturais de compostos com esta propriedade (Morais et al., 2016).

Schinus terebinthifolius Raddi, pertencente à família Anacardiaceae, é uma planta medicinal nativa do Brasil, comumente conhecida como aroeira ou pimenta-do-reino. As atividades anti-microbianas, anti-inflamatória e antioxidante já foram relatadas para essa espécie. O extrato metanólico de suas raízes apresentou altas quantidades de compostos fenólicos, fazendo com que o excesso de radicais livres fossem diminuindo, levando a diminuição de desenvolvimento de algumas patologias, como câncer, diabetes, hipertensão (Rocha et al., 2019).

Achyrocline satureioides (Asteraceae), popularmente conhecida como "macela ou marcela" é uma erva anual aromática de tamanho médio, comumente encontrado na América tropical e subtropical. No sul do Brasil, a erva medicinal A. satureioides é tradicionalmente coletada na "sexta-feira santa". Esta coleta é realizada antes do nascer do sol e as flores secas naturalmente são utilizadas ao longo do ano para tratar diversos distúrbios gastrointestinais. Estudos indicam que a infusão de A. satureioides, como é popularmente usada, tem efeito antioxidante em diferentes sistemas e em baixas doses (Salgueiro et al., 2016).

No estudo desenvolvido por Oliveira et al. (2017), foi investigado o extrato etanólico da espécie Leonurus sibiricus L., conhecida popularmente no Brasil como “erva-de-macaé”, é uma planta difundida do Brasil, principalmente região sul e sudeste. 
Os resultados apontam que o extrato induziu efeitos antioxidantes, antinociceptivos e anti-inflamatórios tópicos, o que favorece seu uso medicinal. Os ensaios antioxidantes realizados in vitro foram os do radical DPPH, sequestro do radical ABTS (2,2'azino-bis (3-etilbenzotiazolin) 6-ácido sulfônico), eliminação de óxido nítrico, inibição da peroxidação lipídica. Foram realizados também testes in vivo em camundongos, teste de formalina e inflamação da orelha induzida por TPA para avaliação da atividade antinociceptiva e anti-inflamatória. Este extrato também levou ao consumo dos radicais DPPH, ABTS e óxido nítrico, aumentou o poder redutor/antioxidante férrico (FRAP) e inibiu a peroxidação lipídica in vitro espontânea ou induzida por $\mathrm{FeSO}_{4}$. $\mathrm{No}$ teste da formalina, o pré-tratamento oral com o extrato reduziu o tempo de lamber/morder na segunda fase. Na inflamação do ouvido induzida por TPA (acetato de tetradecanoilforbol) um potente promotor de tumor, a administração tópica concomitante do extrato reduziu significativamente o edema, a atividade da mieloperoxidase, os níveis de fator de necrose tumoral- $\alpha$ e interleucina-1 $\beta$ e lipoperoxidação, bem como o aumento da FRAP em tecido da orelha quando comparado às orelhas tratadas com veículo.

Já o estudo desenvolvido por Silva et al. (2017), teve como objetivo investigar a atividade hepatoprotetora e antioxidante in vivo e as atividades anti-inflamatórias in vitro da fração acetato de etila obtida do extrato etanólico das folhas de Vernonia condensata Baker. A atividade antioxidante foi avaliada pelo ensaio TBARS (Thiobarbituric acid reactive substances) e pela medição das atividades da glutationa redutase (GSH), SOD e catalase (CAT) no tecido hepático de ratos. Foi observada que o extrato inibiu a formação de malondialdeído, manteve a catalase e aumentou as atividades da glutationa redutase. Observou que o extrato foi capaz de inibir a formação de MDA e aumentar a atividade de GSH, manteve níveis de CAT semelhantes aos do grupo normal, evitou o estresse oxidativo causado pela administração do paracetamol, reafirmando sua capacidade protetora. Além disso, o ácido clorogênico e os flavonoides luteolina e apigenina foram encontrados no extrato etanólico da planta, estes com atividade antioxidante.

Ascari et al. (2019) analisaram a composição química dos óleos essenciais obtidos das folhas das espécimes masculina e feminina da planta Baccharis punctulata, popularmente conhecida como "chíllka-saru-saru", além de avaliar suas propriedades anti-inflamatórias e antioxidantes. A atividade anti-inflamatória in vivo foi avaliada utilizando o modelo de edema de orelha induzido por TPA (12-O-tetradecanoilforbol-13-acetato), além da avaliação de espécies reativas de oxigênio (EROs), como potencial antioxidante in vitro, pelo ensaio de radical livre DPPH. Estudos demonstraram que o tratamento reduziu o influxo de células inflamatórias, portanto a redução de EROs pode estar associada a uma redução do número de células produtoras no tecido inflamado. Esses resultados corroboram o teste DPPH, que apresentou atividade significativa em relação ao ácido ascórbico, utilizado como controle no ensaio, sugerindo que o óleo essencial possui propriedade antioxidante in vitro (Ascari et al., 2019).

Triplaris gardneriana Wedd, pertencente à família Polygonaceae, é popularmente como pajeú ou Pau-formiga. É uma espécie arbórea do semiárido brasileiro com uso na prática popular como anti-inflamatória, anódina, gastroprotetora e hipolipemiante. O estudo investigou a bioacessibilidade do extrato etanólico das sementes por meio da determinação da composição fenólica (determinado pelo método de Folin-Ciocalteu) e da atividade antioxidante in vitro por meio dos ensaios de eliminação do radical DPPH, teste do poder antioxidante redutor férrico (FRAP). Com esses testes, observou-se um aumento na capacidade antioxidante total por DPPH e FRAP no período de 1 e 4 h após a administração, respectivamente. Os resultados apontam que a T. gardneriana provou ser uma fonte significativa de flavonoides bioacessíveis (Lopes Neto et al., 2017).

Cesário et al. (2018) avaliaram a atividade antioxidante e gastroprotetora do extrato hidroalcóolico das folhas de Tocoyena formosa (Cham. \& Schlecht.) K. Schum (HELTF), popularmente conhecida como “jenipapo do campo", sendo muito utilizada na medicina tradicional para morbidades inflamatórias e sintomas gástricos. Estudos realizados pelo mesmo grupo de pesquisadores em 2018 confirmaram a atividade anti-inflamatória e antinociceptiva da espécie. Foi observado efeito antioxidante pelos métodos de redução do ferro (FRAP) e pelo método do DPPH. O ensaio antioxidante de HELTF revelou um EC 50 de 


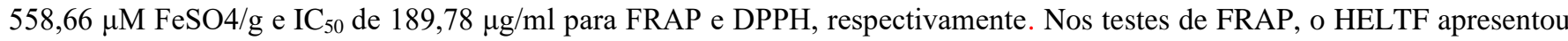
atividade antioxidante mais eficaz do que a vitamina C, utilizado como controle positivo (Cesário et al., 2018).

No estudo desenvolvido por Nascimento et al. (2018) o objetivo foi quantificar a composição de compostos fenólicos e carotenoides presentes nos frutos em diferentes estágios de maturação (verdes, intermediários e maduros) da espécie Malpighia glabra, popularmente conhecida como "acerola", por meio de cromatografia líquida de alta eficiência (HPLC), e avaliar seu potencial antioxidante através de três métodos: atividade quelante do ferro $\left(\mathrm{Fe}^{2+}\right)$, inibição do radica DPPH e inibição da produção de substâncias reativas ao ácido tiobarbitúrico (TBARS). A análise por HPLC identificou a presença de compostos fenólicos e carotenoides na fração metanólica de $M$. glabra nas diferentes maturações utilizadas no estudo. Ensaios antioxidantes indicaram resultados significativos, que podem estar relacionados aos compostos fenólicos presentes e sua interação. A fração metanólica da polpa liofilizada de frutos verdes apresentou melhores resultados nos testes de quelação de ferro e DPPH; TBARS pela fração metanólica dos frutos maduros apresentou menor $\mathrm{IC}_{50}$ como basal. Quando na presença de ferro como indutor de peroxidação, a fração metanólica da polpa dos frutos verdes apresentou o menor $\mathrm{IC}_{50}$. Os resultados indicam que os frutos de M. glabra possuem um bom potencial na eliminação de radicais livres e podem ser uma importante fonte de compostos fitoquímicos antioxidantes (Nascimento et al., 2018).

Cochlospermum regium (Schrank) Pilg.,família Bixaceae, popularmente conhecida como "algodãozinho" ou "algodãozinho-do-campo", é uma planta do cerrado conhecida por seus efeitos anti-inflamatórios. Pedroso et al. (2017), analisaram os compostos constituintes das raízes de C. regium e avaliar os efeitos antioxidantes, antiglicantes, antidiabéticos e anticolinérgicos de seu extrato hidrometanólico por meio de modelos experimentais in vitro e in vivo. Os resultados demonstraram que o extrato hidrometanólico possui alto teor de compostos fenólicos totais e de flavonoides, o que poderia justificar sua atividade antioxidante. O extrato demonstrou inibir a atividade do radical livre DPPH e ABTS em taxas melhores do que o ácido ascórbico. De fato, a atividade antioxidante do extrato, quando analisada através da inibição $\beta$-caroteno/ácido linoléico e oxidação do MDA, foi equivalente ao padrão da quercetina. Esses resultados sugerem que os compostos fenólicos são provavelmente os principais componentes antioxidantes da planta (Pedroso et al., 2017).

Spondias mombin L. é uma planta pertencente à família Anacardiaceae. Esta espécie é nativa do Brasil e seus frutos são comumente conhecidos como "cajá". Este estudo avaliou o extrato hidroetanólico das folhas da S. mombin quanto ao seu potencial anti-inflamatório em modelo in vivo e o potencial antioxidante uma vez que o estresse oxidativo é um importante aspecto associado à inflamação e a citotoxicidade contra células 3T3. No ensaio DPPH foi observada uma potencial doação de elétrons ou íons $\mathrm{H}^{+}$com valores variando de eliminação de $66 \%$ a $76 \%$ para todas as amostras testadas que foram capazes de sequestrar radicais livres. No ensaio de poder redutor para avaliação da capacidade redutora observou-se resultado positivo para todas as amostras analisada. Além disso, foi observado que todas as amostras testadas para a atividade sequestrante do radical hidroxila apresentaram porcentagem de sequestro superior a 100\% (Cabral et al., 2016).

A espécie Eugenia brasiliensis, pertencente à família Myrtaceae, é conhecida pelos nomes "grumixama", "grumixameira" e "cereja-brasileira". O estudo conduzido por Lima et al. (2017) investigou os efeitos in vivo da administração crônica de extrato hidroalcoólico bruto e do extrato acetônico obtido das folhas de espécies de E. brasiliensis sobre a hipertrigliceridemia e o estresse oxidativo causados pela administração crônica de óleo de coco em modelo animal de ratos Wistar. Foram realizados testes de substâncias reativas ao ácido tiobarbitúrico (TBARS), que tem como objetivo medir a produção do malondialdeído (MDA), um produto da lipoperoxidação por radicais livres hidroxila. O conteúdo e as atividades das enzimas antioxidantes catalase (CAT), superóxido dismutase (SOD) e glutationa peroxidase (GSH-px) foram avaliados no sangue e nos fígados dos ratos (Lima et al., 2017). Os resultados mostraram que ambos os extratos foram capazes de prevenir a hipertrigliceridemia e causaram o aumento do TBARS. Também alteraram os parâmetros de estresse oxidativo, conforme demonstrado por um aumento na atividade de CAT e diminuição nas atividades de SOD e GSH-Px. As atividades reduzidas 
das enzimas SOD e GSH-Px aumentam os níveis de ânion superóxido e $\mathrm{H}_{2} \mathrm{O}_{2}$, favorecendo a formação de radicais hidroxila, que danificam lipídios, proteínas e DNA. Esses resultados indicam que os extratos podem ter efeitos hipolipemiantes e antioxidantes (Lima et al., 2017).

Annona muricata Linn, pertencente a família Annonaceae, é popularmente conhecida como "graviola". Essa planta é utilizada na medicina tradicional incluindo o tratamento de hipertensão, diabetes, dor de estômago, febre, infecções parasitárias, vômitos e câncer. Justino et al, (2018) investigou O extrato etanólico das folhas de A. muricata como fonte de compostos antioxidantes e com potencial antidiabético (Justino et al., 2018). Como os métodos de capacidade antioxidantes são baseados em diferentes mecanismos de reação antioxidante, foram realizados três métodos diferentes, sendo eles: o ensaio ORAC, o método da capacidade de absorção do radical de oxigênio (ORAC) é baseado na inibição da oxidação induzida pelo radical peroxil iniciada pela decomposição térmica do 2-amidino-propano(AAPH), o ensaio FRAP, o método de redução do poder antioxidante férrico (FRAP) que é baseado na redução de $\mathrm{Fe}^{3+}$ para $\mathrm{Fe}^{2+}$, que é quelado por 2,4,6-tris (2-piridil)-s-triazina (TPTZ) para formar Fe Complexo ${ }^{2+}$ e por fim o ensaio do DPPH, metodologia que já foi relatada anteriormente. Foi demonstrado que as frações de acetato de etila possuem propriedades antioxidantes e capacidade de reduzir a peroxidação lipídica hepática (Justino et al., 2018).

Hymenaea cangaceira pertence à família Fabaceae, é uma planta medicinal brasileira amplamente conhecida como "Jatobá”, “jetaí”, "jataí-uva”, "jetaíba”. Na medicina popular, é utilizado no tratamento de infecções, problemas respiratórios, reumatismo, antitumoral, inflamação e dor. Neste estudo, investigaram a composição química do óleo essencial de $H$. cangaceira, bem como as atividades antimicrobiana, antinociceptiva e antioxidante e proteção contra danos ao DNA. Os resultados demonstraram alto teor de sesquiterpenos de hidrocarbonetos alta atividade antioxidante e proteção do DNA de danos. A avaliação da atividade antioxidante foi realizada através dos radicais DPPH, ABTS, $\mathrm{O}_{2}{ }^{-}$e $\mathrm{OH}^{-}$. A eliminação do radical $\mathrm{ABTS}^{+}$ pelo óleo foi maior que a do radical $\mathrm{DPPH}^{+}$. Com esssa metodologia, pode-se concluir que óleo essencial de H. cangaceria possui um grande potencial antioxidante em todas as metodologias analisadas (Veras et al., 2020).

\subsubsection{Constituintes químicos responsáveis pela atividade antioxidante}

Produtos naturais tem a capacidade de produzir antioxidantes naturais. Essas substâncias protegem as células dos danos induzidos por espécies oxidativas reativas (EROs) que estão envolvidas em vários processos celulares. Porém, caso essas substâncias não sejam adequadamente reguladas pelo sistema antioxidante, essas EROs podem iniciar uma série de efeitos não benéficos (Chandrasekaran et al., 2017; Poprac et al., 2017). A enzima superóxido dismutase é responsável pela catálise e dismutação do ânion superóxido $\left(\mathrm{O}_{2}{ }^{*}\right)$ resultando em peróxido de hidrogênio $\left(\mathrm{H}_{2} \mathrm{O}_{2}\right)$, sendo esta uma espécie menos reativa que pode ser substrato para outras enzimas responsáveis pelo sistema antioxidante. Na presença de metais de transição, como o ferro $\left(\mathrm{Fe}^{2+}\right)$, o $\mathrm{H}_{2} \mathrm{O}_{2}$ pode ser modificado e gerar um radical hidroxila tóxico $\left(\mathrm{OH}^{-}\right)$. Para que o $\mathrm{OH}^{-}$seja decomposto em $\mathrm{H}_{2} \mathrm{O}$ as enzimas antioxidantes mais eficientes são a catalase (CAT) e/ou glutationa peroxidase (GPx) (Carvalho et al., 2019).

Os compostos fenólicos, como flavonoides, ácidos fenólicos e terpenos são metabólitos secundários encontrados principalmente em plantas e desempenham um papel importante no tratamento de distúrbios metabólicos por causa de seu papel antioxidante, podendo agir como captadores de radicais livres (Lima Júnior et al., 2021). Os estudos têm demonstrado que os compostos polifenólicos, principalmente os flavonoides, são compostos bioativos com propriedades antioxidantes que podem ser utilizados para fins terapêuticos em doenças como crônico-degenerativas. O mecanismo potencial dos flavonoides contra os agentes oxidantes ocorre possivelmente pois esses compostos podem doar átomos de hidrogênio aos radicais lipídicos e produzir derivados lipídicos e radicais antioxidantes, que são mais estáveis e menos disponíveis para promover a auto-oxidação (Lima et al., 2017; Cesário et at., 2018). 
Pereira et al. (2020) relatou pela primeira vez a participação de alguns heterosídeos fenólicos polares concentrados na partição de butanol, como miquelianina, isoquercitrina, quercitrina, caempferol-3-O-pentose, afzelina e isorhamnetinaglucuronídeo que se mostraram responsáveis pela atividade antioxidante da espécie Ocotea notata. Nesse mesmo estudo os compostos kaempferol-3-O-pentose e isorhamnetina-glucuronídeo foram relatados pela primeira vez para esta espécie.

Em análises de prospecção fitoquímica do extrato etanólico de Anacardium humile e suas frações orgânicas mostraram uma presença marcante de polifenóis, principalmente nas frações diclorometano, acetato de atila e butanol. Dentre essas moléculas, destacam-se as que já são conhecidas por sua capacidade antioxidante, como a catequina, a quercetina e a quercetina glicosilada, além do ácido gálico, kaempferol e naringenina. Da mesma forma, o ácido anacárdico, comumente encontrado no gênero Anacardium, provou ser uma importante molécula antioxidante (Lima Júnior et al., 2021).

Vários compostos fenólicos também foram encontrados no extrato de Alibertia edulis como ácido cafeico, quercetina 3-rhamnosil- $(1 \rightarrow 6)$-galactosídeo, ioxido de iridois, ácido cafeico, ácido ferúlico e rutinas. Ácidos fenólicos bioativos, flavonoides e iridoides têm se mostrado responsáveis por várias das ações farmacológicas atribuídas a espécies da família Rubiaceae, citando hipotensivas, anti-hipertensivas e diuréticas (Aquino et al., 2020).

$\mathrm{O}$ extrato aquoso da espécie Stryphnodendron adstringens apresentou atividade antioxidante eliminando os radicais livres ABTS e 2,2-difenil-1-picril-hidrazil (DPPH), que está diretamente relacionado com a alta concentração de compostos fenólicos. Dentre esses compostos os taninos são os mais descritos para esta espécie, como ácido gálico, galocatequina, epigalocatequina e proantocianidinas diméricas e triméricas (taninos condensados), compostos principalmente de prodelfinidina juntamente com procianidina e prorobinetidina (Baldivia et al., 2018).

A avaliação fitoquímica dos extratos da Cnidoscolus phyllacanthus possibilitou a análise qualitativa dos seus metabólitos secundários, onde se pode evidenciar nos extratos em hexano das folhas e galhos a presença de flavonoides do tipo flavonas, flavonóis e xantonas bem como triterpenoides pentacíclicos livres em suas raízes. Observou-se novamente a presença de flavonas, flavonóis e xantonas em suas folhas, agora no extrato em etanol. Além disso, foi possível a determinação de saponinas nos extratos em etanol das raízes e catequinas e flavanonas nos galhos. Já nos extratos em água, as folhas apresentaram testes positivos nas análises de fenóis, flavonoides e xantonas e os galhos para fenóis, flavonoides e xantonas e saponinas (Morais et al., 2016).

Propriedades antioxidantes de Achyrocline satureioides foram realizadas por diferentes análises tais como determinação da capacidade antioxidante total, atividades sequestrantes DPPH e ABTS e ensaio FRAP. Assim, pode-se considerar que a capacidade de sequestrar radicais livres in vitro pode ser genericamente comparada à capacidade de neutralizar radicais livres endógenos, como o radical hidroxila $\left(\mathrm{OH}^{-}\right)$, o mais prejudicial dos radicais encontrados biologicamente. Todos esses efeitos se dão pela presença de isoquercetina, quercetina e ácido caféico (Salgueiro et al., 2016).

Embora a espécie $B$. forficata já tenha um uso bem estabelecido no Brasil, seus constituintes químicos foram descobertos recentemente, bem como seus efeitos farmacológicos comprovados. Dentre os compostos dessa espécie, destaca-se o flavonoide kaempferitrina, responsável pela maioria dos seus efeitos, dentre eles um elevado efeito antioxidante (Franco et al., 2020).

Pode-se ainda classificar a atividade antioxidante de acordo com seu $\mathrm{IC}_{50}$, sendo a atividade considerada excelente $\left(\mathrm{IC}_{50}\right.$ $<15 \mu \mathrm{g} / \mathrm{mL})$, boa $\left(15 \mu \mathrm{g} / \mathrm{mL}<\mathrm{IC}_{50}<50 \mu \mathrm{g} / \mathrm{mL}\right)$, média $\left(50 \mu \mathrm{g} / \mathrm{mL}<\mathrm{IC}_{50}<100 \mu \mathrm{g} / \mathrm{mL}\right)$ e atividade fraca $\left(\mathrm{IC}_{50} 100 \mu \mathrm{g} / \mathrm{mL}\right)$. De acordo com essa classificação o óleo essencial isolado da espécie de Aniba rosaeodora linalol foi considerado como uma atividade antioxidante ótima corroborando com estudos anteriores que verificaram excelente atividade antioxidante das espécies de Aniba, evidenciado pela técnica de descoloração do radical 2,20-Azino-bis (ácido 3-etilbenzotiazolina-6-sulfônico) (ABTS), inibindo totalmente o radical em concentrações relativamente baixas (Teles et al., 2021). 
No extrato etanólico de Leonurus sibiricus L., foram realizadas a determinação dos teores fenólicos e de flavonoides totais e, dentre os compostos identificados, o ácido caféico foi detectado em maior quantidade, seguido pelo ácido clorogênico, ácido ferúlico, quercetina e ácido $p$ - cumárico (Oliveira et al., 2017).

Annona muricata Linn, os compostos identificados pela análise HPLC-MS são amplamente relatados como antioxidantes potentes, como ácido clorogênico, procianidinas B2 e C1, epicatequina, quercetina, quercetina-glicosídeo, rutina e caempferol. Essas moléculas têm atividades de eliminação de radicais livres e estão associadas à capacidade de redução de hidrogênio ou como agentes doadores de elétrons (Justino et al., 2018).

A atividade antioxidante da Tocoyena formosa pode estar relacionada à sua composição fitoquímica, pois possui as seguintes classes de metabólitos secundários: taninos condensados, flavonoides, flavonóis, xantonas, chalconas, auronas, flavonas, catequinas, triterpenóides pentacíclicos e saponinas que apresentam atividade antioxidante (Cesário et al., 2018).

Entre os componentes identificados em C. regium são fenólico específico e compostos flavonoides, incluem campferol , naringenina, aromadendrine, e di-hidrocaempferol-3-O- $\beta$-glucopiranósido, o ácido gálico e ácido elágico todos os quais têm mostrado possuir atividade antioxidante (Pedroso et al., 2017).

Spondias mombin L apresenta grande quantidade de derivados fenólicos e flavonoides. A análise qualitativa do extrato HE permitiu indicar a ocorrência de três compostos fenólicos principais: ácido clorogênico, ácido elágico e isoquercetina, sugerimos que os ácidos fenólicos presentes no extrato e frações de S. mombin podem contribuir para a atividade antioxidante do extrato. Verificou-se que o ácido clorogênico e o ácido elágico contribuem ainda para a ação farmacológica desta espécie (Cabral et al, 2016).

\section{Conclusão}

A inflamação desempenha um papel crítico no processo fisiopatológico de várias doenças e tornou-se um alvo terapêutico imperativo no desenvolvimento de novas abordagens para intervenções farmacológicas. As plantas medicinais surgem como uma fonte de inspiração para novos fármacos e/ou produtos terapêuticos, na busca de intervenções com menos efeitos indesejáveis e com melhor custo-benefício. Nesse sentido, este trabalho descreve alguns dos estudos recentes que investigaram a distribuição, a morfologia e os benefícios farmacológicos de diferentes plantas medicinais brasileiras com a atividade anti-inflamatória e antioxidante, através dos seus constituintes fitoquímicos isolados ou em complexo, a exemplo dos óleos essenciais ou dos extratos.

Observou-se também que os mecanismos de ação não são totalmente elucidados e um estudo sobre os efeitos colaterais e as potenciais interações entre as plantas medicinais e outras drogas sintéticas também devem ser o próximo passo para se prosseguir na descoberta de produtos terapeuticamente promissores. Por fim, os resultados encontrados sugerem um grande potencial na flora brasileira para a descoberta e caracterização de novas espécies vegetais, e compostos isolados destas, com atividades anti-inflamatórias e antioxidantes, carecendo-se de maiores incentivos dos órgãos de fomento para que as pesquisas sigam às etapas subsequentes de desenvolvimento de novos fármacos ou de medicamentos fitoterápicos.

\section{Referências}

Alcântara, B. G. V., Oliveira, F. P., Katchboria, A. et al. (2021). Confirmation of ethnopharmacological anti-inflammatory properties of Ocotea odorifera and determination of its main active compounds. Journal of Ethnopharmacology, 264, 113378-0.

Aquino, D. F. S., Piccinelli, A. C., Soares, F. L. P. et al. (2015). Anti-hyperalgesic and Anti-inflammatory Activity of Alternanthera maritima Extract and 2"O- $\alpha$-L-rhamnopyranosylvitexin in Mice. Inflammation, 38(6), 2057-2066.

Aquino, D. F. S., Monteiro, T. A., Lima Cardoso, C. A. et al. (2020). Investigation of the antioxidant and hypoglycemiant properties of Alibertia edulis (L.C. Rich.) A.C. Rich. leaves. Journal of Ethnopharmacology, 253, 112648. 
Aragão, D. P., Souza, B. S., Brito, T. V. et al. (2017). The anti-inflammatory and antinociceptive activity of albumins from Crotalaria retusa seeds. Biomedicine \& Pharmacotherapy, 93, 536-542.

Arasu, M. V., Al-Dhabi, N. A., Rejiniemon, T. S. et al. (2015). Identification and characterization of Lactobacillus brevis P68 with antifungal, antioxidant and probiotic functional properties. Indian Journal of Microbiology. 55(1), 19-28.

Arasu, M. V., Ilavenil, S., Kim, D. H. et al. (2014). In vitro and in vivo enhancement of adipogenesis by Italian ryegrass (Lolium multiflorum) in 3T3-L1 cells and mice. Plos one, 9 (1), 85297.

Ascari, J., De Oliveira, M. S., Nunes, D. S. et al. (2019). Chemical composition, antioxidant and anti-inflammatory activities of the essential oils from male and female specimens of Baccharis punctulata (Asteraceae). Journal of Ethnopharmacology, 234, 1-7.

Ashley, N. T., Weil, Z. M. \& Nelson, R. J. (2012). Inflammation: mechanisms, costs, and natural variation. Annual Review of Ecology, Evolution, and Systematics, 43, 385-406.

Azevedo, L. F., Silva, S. M., Navarro, L. B. et al. (2016). Evidence of anti-inflammatory and antinociceptive activities of Plinia edulis leaf infusion, Journal of Ethnopharmacology, 192, 178-182.

Baldivia, D., Leite, D., Castro, D. et al. (2018). Evaluation of In Vitro Antioxidant and Anticancer Properties of the Aqueous Extract from the Stem Bark of Stryphnodendron adstringens. International Journal of Molecular Sciences, 19(8), 2432.

Balin, P. S., Zanatta, F. C., Jorge, B. C. et al. (2018). Toxicological evaluation and anti-inflammatory potential of an ethanolic extract from Bromelia balansae (Bromeliaceae) fruit. Journal of Ethnopharmacology, 222, 79-86.

Barros, M., Silva, L. M., Boeing, T. et. al. (2016). Pharmacological reports about gastroprotective effects of methanolic extract from leaves of Solidago chilensis (Brazilian arnica) and its components quercitrin and afzelin in rodents. Naunyn-Schmiedeberg's Archives of Pharmacology, 389(4), $403-17$.

Bhattacharya S. (2017). Medicinal plants and natural products in amelioration of arsenic toxicity: a short review. Pharmaceutical Biology, 55, 349-354.

Boff, L., Silva, I. T., Argenta, D. F. et al. (2016). Strychnos pseudoquina A. St. Hil.: a Brazilian medicinal plant with promising in vitro antiherpes activity. Journal of Applied Microbiology, 121(6), 1519-1529.

Brandenburg, M. M., Rocha, F. G., Pawloski, P. L. et al. (2020). Baccharis dracunculifolia (Asteraceae) essential oil displays anti-inflammatory activity in models of skin inflammation. Journal of Ethnopharmacology, 259, 112840-0.

Brasil. Ministério Da Saúde. (2020). Portal da Saúde: Relação Nacional de Medicamentos Essenciais (RENAME). http://bvsms.saude.gov.br/bvs/publicacoes/relacao_medicamentos_rename_2020.pdf>

Cabral, B., Siqueira, E. M. S., Bitencourt, M. A. O. et al. (2016). Phytochemical study and anti-inflammatory and antioxidant potential of Spondias mombin leaves. Revista Brasileira de Farmacognosia, 26(3), 304-311.

Carneiro, N. V. Q., Silva, H. B. F., Silva, R. R. et al. (2019). Sambucus australis Modulates Inflammatory Response via Inhibition of Nuclear Factor Kappa B (NF-kB) in vitro. Anais da Academia Brasileira de Ciências, 91(1), e20170831.

Carvalho, T. G. J., Baldivia, D. S., Leite, D. F. et al. (2019). Medicinal Plants from Brazilian Cerrado: Antioxidant and Anticancer Potential and Protection against Chemotherapy Toxicity. Oxidative Medicine and Cellular Longevity, 1-16.

Cesário, F. R., Rodrigues, A. T., Fernandes da Silva, B. A. et al. (2018). Evaluation of the antioxidant and gastroprotective activity and HPLC analysis of the hydroalcoholic extract of Tocoyena formosa leaves (Cham. \& Schlecht) K. Schum. Food and Chemical Toxicology, 11, $355-362$.

Chandrasekaran, A., Idelchik, M. P. S., \& melendez, J. A. (2017). Redox control of senescence and age-related disease, Redox Biology, 11, 91-102.

De Vargas, F. S., Almeida, P. D. O., De Boleti, A. P. A. et al. (2016). Antioxidant activity and peroxidase inhibition of Amazonian plants extracts traditionally used as anti-inflammatory. BMC Complementary and Alternative Medicine, 16(1), 83.

Dutra, R. C., Campos, M. M., Santos, A. R. S. et al. (2016). Medicinal plants in Brazil: Pharmacological studies, drug discovery, challenges and perspectives. Pharmacological Research, 112, 4-29.

El-Guezzane, C., El-moudden, H., Harhar, H. et al. (2021). A comparative study of the antioxidant activity of two Moroccan prickly pear cultivars collected in different regions. Chemical Data Collections, 31, 100637.

Franco, R. R., Alves, V. H. M., Zabisky, L. F. R. et al. (2020). Antidiabetic potential of Bauhinia forficata Link leaves: a non-cytotoxic source of lipase and glycoside hydrolases inhibitors and molecules with antioxidant and antiglycation properties. Biomedicine \& Pharmacotherapy, 123 , 109798.

Guo, B. J., Bian, Z. X., Qiu, H. C. et al. (2017). Biological and clinical implications of herbal medicine and natural products for the treatment of inflammatory bowel disease. Annals of the New York Academy of Sciences, 1401(1), 37-48.

Gusman, G. S., Campana, P. R., Castro, L.C. et al. (2015). Evaluation of the Effects of Some Brazilian Medicinal Plants on the Production of TNF- $\alpha$ and CCL2 by THP-1 Cells. Evidence-Based Complementary and Alternative Medicine, 2015, 497123.

Harirforoosh, S., Asghar, W. \& Jamali, F. (2013). Adverse effects of nonsteroidal anti-inflammatory drugs: An update of gastrointestinal, cardiovascular and renal complications. Journal of Pharmaceutical Sciences, 16, 821-847.

Justino, A. B., Miranda, N. C., Franco, R. R. et al. (2018). Annona muricata Linn. leaf as a source of antioxidant compounds with in vitro antidiabetic and inhibitory potential against $\alpha$-amylase, $\alpha$-glucosidase, lipase, non-enzymatic glycation and lipid peroxidation. Biomedicine and Pharmacotherapy, $100,83-92$. 
Kim, S. J., Rahman, M. M., Lee, M. K. et al. (2014). Identification and quantification of volatile and phenolic compounds composition in Buck wheat Sprouts by GC/MS and HPLC. Asian Journal of Chemistry, 26(3), 777.

Komakech, R., Kim, Yong-Goo., Matsabisa, G. M. et al. (2019). Anti-inflammatory and analgesic potential of Tamarindus indica Linn. (Fabaceae): a narrative review. Integrative Medicine Research, 8(3), 181-186.

Kuraoka-Oliveira, A. M., Radai, J. A. S., Leitão, M. M. et al. (2020). Anti-inflammatory and anti-arthritic activity in extract from the leaves of Eriobotrya japonica. Journal Of Ethnopharmacology, 249, 112418-0.

Lima Júnior, J. P., Franco, R. R., Saraiva, A. L. et al. (2021). Anacardium humile St. Hil as a novel source of antioxidant, antiglycation and $\alpha$-amylase inhibitors molecules with potential for management of oxidative stress and diabetes. Journal of Ethnopharmacology, $268,113667$.

Lima, A. B., Delwing-de Lima, D., Vieira, M. R. et al. (2017). Hypolipemiant and antioxidant effects of Eugenia brasiliensis in an animal model of coconut oilinduced hypertriglyceridemia. Biomedicine and Pharmacotherapy, 96, 642-649.

Lopes Neto, J. J., De Almeida, T. S., De Medeiros, J. L. et al. (2017). Impact of bioaccessibility and bioavailability of phenolic compounds in biological systems upon the antioxidant activity of the ethanolic extract of Triplaris gardneriana seeds. Biomedicine Pharmacotherapy, 88, 999-1007.

Lorençoni, M. F., Figueira, M. M., Silva, M. V. T. (2020). Chemical composition and anti-inflammatory activity of essential oil and ethanolic extract of Campomanesia phaea (O. Berg.) Landrum leaves. Journal of Ethnopharmacology, 252, 112562-0.

Medzhitov, R. (2008). Origin and physiological roles of inflammation. Nature, 454, 428-435.

Moraes, S. Z. C., Shan, A. Y. K. V., Melo, M. A. O. et al. (2020). Antinociceptive and anti-inflammatory effect of Poincianella pyramidalis (Tul.) L.P. Queiroz. Journal of Ethnopharmacology, 254, 112563-0.

Morais, N. R. L., Oliveira Neto, F. B., Melo, A. R. et al. (2016). Prospecção fitoquímica e avaliação do potencial antioxidante de Cnidoscolus phyllacanthus (müll. Arg.) Pax \& k.hoffm. Oriundo de apodi - RN. Revista Brasileira de Plantas Medicinais, 18(1), 180-185.

Muller, C. M. S., Coelho, G. B., Araújo, M. C. P. M. et al. (2019). Lychnophora pinaster ethanolic extract and its chemical constituents ameliorate hyperuricemia and related inflammation. Journal of Ethnopharmacology, 242, 112040.

Narayanasamy K. \& Ragavan B. (2012). In vitro antioxidant activity of Zanthozylum Tetraspermum (W\&A) stem bark. International Journal of Engineering, Science and Technology. 4, 155-62.

Nascimento, E. M. M., Rodrigues, F. F. G., Costa, W. D. et al. (2018). HPLC and in vitro evaluation of antioxidant properties of fruit from Malpighia glabra (Malpighiaceae) at different stages of maturation. Food and Chemical Toxicology, 119, 457-463.

Newman, D. J. \& Cragg, G. M. (2012). Natural products as sources of new drugs over the 30 years from 1981 to 2010. Journal of Natural Products, 75, 311 335 .

Oliveira, A. S., Cercato, L. M., De Santana, M. T. S. et al. (2017). The ethanol extract of Leonurus sibiricus L. induces antioxidant, antinociceptive and topical anti-inflammatory effects. Journal of Ethnopharmacology, 206, 144-151.

Oliveira, C. C. O., Matos, N. A., Veloso, C. C. et al. (2019). Anti-inflammatory and antinociceptive properties of the hydroalcoholic fractions from the leaves of Annona crassiflora Mart. in mice. Inflammopharmacology, 27, 397-408.

Pedroso, T. F., Bonamigo, T. R., Da Silva, J. et al. (2017). Chemical constituents of Cochlospermum regium (Schrank) Pilg. root and its antioxidant, antidiabetic, antiglycation, and anticholinesterase effects in Wistar rats. Biomedicine and Pharmacotherapy, 111, $1383-1392$.

Pereira, R. V., Mecenas, A. S., Malafaia, C. R. A. et al. (2020). Evaluation of the chemical composition and antioxidant activity of extracts and fractions of Ocotea notata (Ness) Mez (Lauraceae). Natural Product Research, 34, 3004-3007.

Poprac, P., Jomova, K., Simunkova, M. et al. (2017). Targeting free radicals in oxidative stressrelated human diseases, Trends in Pharmacological Sciences, $38(7), 592-607$

Quintans-Júnior, L. J., Gandhi, S. R., Passos, F. R. S. et al. (2020). Dereplication and quantification of the ethanol extract of Miconia albicans (Melastomaceae) by HPLC-DAD-ESI-/MS/MS, and assessment of its anti-hyperalgesic and anti-inflammatory profiles in a mice arthritis-like model: evidence for involvement of tnf- $\alpha$, il-1 $\beta$ and il-6. Journal of Ethnopharmacology, 258, 112938-0.

Ribeiro, V. P., Arruda, C., El-Salam, M. A. et al. (2018). Brazilian medicinal plants with corroborated anti-inflammatory activities: a review, Pharmaceutical Biology, 56(1), 253-268

Rocha, P. S. R., Boleti, A. P. A., Vieira, M. C. V. et al. (2019). Microbiological quality, chemical profile as well as antioxidant and antidiabetic activities of Schinus terebinthifolius Raddi. Comparative Biochemistry and Physiology Part C: Toxicology \& Pharmacology, 220, 36-46.

Salgueiro, A. C. F., Folmer, V., Rosa, H. S. et al. (2016). In vitro and in silico antioxidant and toxicological activities of Achyrocline satureioides. Journal of Ethnopharmacology, 194, 6-14.

Salomé, D. C., Cordeiro, N. M., Valério, T. S. et al. (2020). Aristolochia trilobata: Identification of the Anti-Inflammatory and Antinociceptive Effects. Biomedicines, 8(5), 111

Santos, E., Leitão, M. M., Ito, C. N. A. et al. (2021). Analgesic and anti-inflammatory articular effects of essential oil and camphor isolated from Ocimum kilimandscharicum Gürke leaves. Journal of Ethnopharmacology, 269, 113697-0. 
Research, Society and Development, v. 10, n. 7, e10310716196, 2021

(CC BY 4.0) | ISSN 2525-3409 | DOI: http://dx.doi.org/10.33448/rsd-v10i7.16196

Silva, J. B. D., Mendes, R. F., Tomasco, V. et al. (2017). New aspects on the hepatoprotective potential associated with the antioxidant, hypocholesterolemic and anti-inflammatory activities of Vernonia condensata Baker. Journal of Ethnopharmacology, 198, 399-406.

Silva, J. C., Araújo, C. S., Lima-Saraiva, S. R. G. et. al. (2015). Antinociceptive and anti-inflammatory activities of the ethanolic extract of Annona vepretorum Mart. (Annonaceae) in rodents. BMC Complementary and Alternative Medicine, 12, 197.

Silva, M. M., Iriguchi, E. K. K., Kassuya, C. A. L. et al. (2017). Schinus terebinthifolius: phenolic constituents and in vitro antioxidant, antiproliferative and in vivo anti-inflammatory activities. Revista Brasileira de Farmacognosia. 27, 445-452.

Silva, T. S. J., Soares, A. A., Rocha, T. M. et al. (2020). Spondias mombin: quality control and anti-inflammatory activity in human neutrophils. Journal of Herbal Medicine, 24, 100393-0.

Souza, J. A., Patel, Y. B. K., Grockoski, H. A. et al. (2021). Toxicological and anti-inflammatory profile of Synadenium grantii Hook. f. in mice. Journal of Ethnopharmacology, 267, 113487-0.

Sperotto, N. D. S., Steffens, L., Veríssimo, R. M. et al. (2018). Wound healing and anti-inflammatory activities induced by a Plantago australis hydroethanolic extract standardized in verbascoside. Journal of Ethnopharmacology, 225, 178-188.

Stein, R., Berger, M., Cecco, B. S. et al. (2021). Chymase inhibition: a key factor in the anti-inflammatory activity of ethanolic extracts and spilanthol isolated from Acmella oleracea. Journal of Ethnopharmacology, 270, 113610-0.

Teles, A. M., Silva-Silva, J. V., Fernandes, J. M. P. et al. (2021). Aniba rosaeodora (Var. amazonica Ducke) Essential Oil: Chemical Composition, Antibacterial, Antioxidant and Antitrypanosomal Activity. Antibiotics, 10(1), 24.

Veras, B. O., Oliveira, J. R. S., Lima, V. L. M. et al. (2021). The essential oil of the leaves of Verbesina macrophylla (Cass.) S.F.Blake has antimicrobial, antiinflammatory and antipyretic activities and is toxicologically safe. Journal Of Ethnopharmacology, 265, 113248-0.

Veras, B., Melo de Oliveira, M. B., Granja, S. O. F. et al. (2020). Chemical composition and evaluation of the antinociceptive, antioxidant and antimicrobial effects of essential oil from Hymenaea cangaceira (Pinto, Mansano \& Azevedo) native to Brazil: A natural medicine. Journal of Ethnopharmacology, 247, 112265 .

Viscardi, D. Z., Arrigo, J. S., Correia, C. A. C. et al. (2017). Seed and peel essential oils obtained from Campomanesia adamantium fruit inhibit inflammatory and pain parameters in rodents. PLoS ONE, 12(2), e0157107.

Wang, B., Deng, J., Gao, Y. et al. (2011). The screening toolbox of bioactive substances from natural products: A review. Fitoterapia, 82, $1141-1151$.

Yang, R., Yuan, B. C., Ma, Y. S.et al. (2017). The anti-inflammatory activity of licorice, a widely used Chinese herb. Pharmaceutical Biology, 55, 5-18. 